\title{
A compreensão dos professores sobre a Alfabetização Científica: perspectivas e realidade para o Ensino de Ciências
}

Josiani Fátima Weimer Baierle Oldoni

josiani.oldoni@gmail.com

Universidade Estadual do Oeste do Paraná (UNIOESTE), Cascavel, Paraná, Brasil

Barbara Grace Tobaldini de Lima barbara.lima@uffs.com Universidade Federal da Fronteira Sul (UFFS), Realeza, Paraná, Brasil

\section{RESUMO}

A alfabetização científica é uma alternativa que torna possível a ressignificação da ciência, na qual prioriza a contextualização do conteúdo e o compromisso com a formação de cidadãos críticos e preparados para participar de discussões sobre os avanços e implicações da ciência. Desse modo, esta pesquisa objetivou compreender como a abordagem da alfabetização científica vêm sendo trabalhada em sala de aula pelos professores de Ciências das escolas da educação básica do município de Planalto, PR. A metodologia que retrata a abordagem do problema de pesquisa é classificada como qualitativa. Para o desenvolvimento do estudo, realizou-se entrevistas com quatro professores de ciências do 9o ano do ensino fundamental das escolas estaduais do município de Planalto, PR. As entrevistas foram analisadas com base na metodologia da Análise Textual Discursiva, no qual emergiram as seguintes categorias: A compreensão dos professores sobre alfabetização científica e Formação permanente. Verificou-se a necessidade de se discutir e repensar os objetivos do ensino de Ciências, afim de proporcionar o processo da Alfabetização Científica pois existem muitas lacunas na compreensão dessa abordagem. Assim, ressalta-se a importância do contínuo processo de formação na carreira do profissional docente.

PALAVRAS-CHAVE: Ensino de ciências. Alfabetização Científica. Formação permanente. 


\section{INTRODUÇÃO}

A Alfabetização Científica é um dos pressupostos do ensino de Ciências. Entretanto, observa-se que o espaço escolar apresenta alguns desafios que dificultam a abordagem da Alfabetização Científica, dentre eles, podemos destacar, métodos pedagógicos com a apresentação de conteúdos dogmáticos desprovidos de reflexões críticas, bem como a presença de lacunas na formação inicial e continuada dos professores.

De acordo com Neto e Fracalanza $(2003$, p.151) os livros didáticos ainda "apresentam erroneamente o conhecimento científico como um produto acabado, elaborado por mentes privilegiadas, desprovidos de interesses políticoeconômicos e ideológicos". Assim, observa-se que as obras didáticas estão carregadas de conteúdos informativos, no qual são trabalhos sem a devida problematização e construção conceitual dos conhecimentos científicos.

Percebe-se que os estudantes possuem acesso a muitas informações, mas sentem dificuldade em perceber quais são significativas, é nesse contexto que o espaço escolar se destaca como cenário de transformação dessas informações em saberes científicos. As práticas pedagógicas devem ser pautadas na contextualização do conhecimento e não apenas na reprodução de informações, pois "se educar é fazer transformações, não é com transmissão de informações que vamos fazer isso" (CHASSOT, 2011, p.29).

Com o intuito de superar as dificuldades presentes no Ensino de Ciências, destaca-se a Alfabetização Científica considerada uma alternativa que torna possível a formação da cultura científica, a ressignificação da Ciência, bem como o desenvolvimento do espírito crítico que possibilita ao estudante compreender e avaliar os impactos que os conteúdos das informações recebidas em diferentes meios podem gerar no contexto social e escolar.

Para Lorenzetti e Delizoicov (2001) a Alfabetização Científica é compreendida como um processo que proporciona a compreensão dos significados das ciências naturais, constituindo-se como um meio para o estudante ampliar seus conhecimentos, sua cultura, como cidadão inserido na sociedade. Além disso, o processo da Alfabetização Científica [...] "deve ter o papel de fomentar a curiosidade e de estimular a procura de respostas que se vinculem às questões da vida prática (MONTENEGRO, 2008, p. 24).

De acordo com as concepções do pedagogo Paulo Freire, a Alfabetização Científica vai além do domínio psicológico e mecânico das técnicas de ler e escrever, ou seja, a Alfabetização Científica corresponde ao domínio dessas técnicas em termos conscientes, é um processo de autoformação que possibilita ao sujeito interferir no contexto que está inserido (FREIRE, 1980).

Sabe-se que a Alfabetização Científica é um dos objetos de investigação das avaliações em larga escala, no qual podemos destacar o Programa Internacional de Avaliação de Alunos (PISA) que abrange três áreas do conhecimento, Leitura, Matemática e Ciências. Para avaliar o desempenho dos estudantes na área do conhecimento de Ciências, utiliza-se como critério a Alfabetização Científica, que traz como objetivo: verificar a capacidade do estudante em se envolver em questões sobre a ciência, sua compreensão sobre as ideias científicas, como um sujeito reflexivo, capaz de participar de discussões sobre ciência e tecnologia (OECD, 2015). 
Diante disso, ressalta-se a importância do desenvolvimento de práticas pedagógicas inerentes a Alfabetização Científica, não só pelo fato de estar presente nas avaliações externas, mas pelas contribuições que geram no modo de vida do indivíduo, pois "só assim é possível formar sujeitos conhecedores da Ciência, socialmente responsáveis e reflexivos, capazes de serem agentes de transformação no meio em que estão inseridos" (ARAúJO et al., 2014, p.25).

Portanto, diante da necessidade da realização de propostas metodológicas sobre a Alfabetização Científica, esta pesquisa objetivou compreender como essa abordagem vem sendo trabalhada em sala de aula pelos professores de Ciências Naturais das escolas estaduais do município de Planalto, Paraná.

\section{O ENSINO DE CIÊNCIAS NO CONTEXTO DA ALFABETIZAÇÃO CIENTÍFICA}

Para os especialistas da área do ensino, a alfabetização científica tornou-se uma exigência urgente, um fator essencial do desenvolvimento das pessoas e da sociedade, também a curto prazo (CACHAPUZ et al., 2011). O reconhecimento da importância da alfabetização científica traz inúmeros debates sobre as metodologias do ensino de Ciências e as necessidades de reformas educativas.

Sendo assim, primeiramente, nos interessa analisar a proposta, bem como os objetivos da expressão Alfabetização Científica. A Alfabetização Científica pode ser considerada como um processo que envolve a relação dos conhecimentos científicos com a vida social do sujeito, o intuito é que o estudante seja capaz de compreender os conhecimentos científicos e ir além da dimensão conceitual, desenvolvendo a capacidade de relacionar esses saberes com as situações presentes em seu cotidiano. Assim, a Alfabetização Científica possibilita ao sujeito a compreensão dos fenômenos e influências da ciência presente no cotidiano, e o desenvolvimento de uma postura mais crítica durante as tomadas de decisões.

Para Cascais, Ghedin, Therán (2011), a Alfabetização Científica se estabelece quando os estudantes passam a compreender as descobertas científicas e a participar de maneira fundamentada nas decisões que afetam a sua vida. Considera-se que a Alfabetização Científica prepara os cidadãos para os "[...] processos de tomada de decisões políticas, evitando que a responsabilidade sobre o desenvolvimento técnico-científico recaia exclusivamente sobre uma pequena elite científica e política supostamente qualificada" (ROTHBERG, QUINATO, 2012, p.02).

A Alfabetização Científica sendo desenvolvida em todos os níveis de educação, estabeleceria contribuições na formação da cultura científica, permitindo um ensino mais democrático, pois sabe-se que o acesso ao conhecimento científico permite ao sujeito desenvolver-se intelectualmente, gerando uma maior responsabilidade social e política.

\footnotetext{
A proposta da educação científica é reconstruir toda a proposta da educação básica, não só para realçar os desafios da preparação científica para a vida e para o mercado, mas principalmente para implantar processos de aprendizagem minimamente efetivos. (DEMO, 2010, p.21).
}

Verifica-se que a maioria dos alunos consideram os conteúdos científicos trabalhados em sala de aula, abstratos e incompreensíveis, pois são apresentados por meio de fórmulas e conceitos teóricos. Propor atividades que exercite a 
imaginação desses alunos, seria uma forma de desenvolver o interesse pelos conteúdos científicos.

Percebe-se que na educação infantil os alunos são curiosos e argumentativos, mas com o passar das séries acabam sendo moldados pelo sistema, o que dificulta o ensino e aprendizado. Existe a necessidade de resgatar o potencial criativo bem como a imaginação e a curiosidade dos alunos durante as propostas de ensino, pois a vontade de conhecer se dá mediante essas características.

Os conteúdos do ensino de Ciências possibilitam o desenvolvimento de propostas didáticas nas quais o professor pode reproduzir muitas atividades desenvolvidas pelos cientistas, demonstrando para os alunos de maneira prática e reflexiva, como se levou a construção do conhecimento, o que facilita o exercício de um ensino mais prazeroso e significativo. Quando se quer estabelecer uma educação científica é necessário que os estudantes sejam defrontados com problemas presentes em seu contexto, ou então, relacionados com os conteúdos já programados, nos quais tenham que realizar hipóteses e posteriormente investigações na tentativa de resolvê-lo.

\begin{abstract}
A educação científica permite o aprimoramento das oportunidades de desenvolvimento científico tais como: utilizar-se dos conhecimentos científicos para elevar a qualidade de vida, tornando estes conhecimentos oportunidades de estilos de vida mais dignos, confiáveis e compartilhados; aproveitar as oportunidades de formação nas áreas científicas e tecnológicas; universalização do acesso aos conhecimentos científicos (DEMO, 2010).
\end{abstract}

Diante da necessidade da educação científica, muito tem-se discutido sobre o processo de Alfabetização Científica. No entanto, pouco se questiona, sobre a real situação na qual a escolas brasileiras se encontram. Chassot (2011) destaca que as situações nas quais a educação é apresentada "favorece o aumento da dominação e contribui para que se posicione ainda mais injustamente os sujeitos" (p.134).

Deste modo, uma das formas de superar esta dominação é proporcionar estratégias de ensino que permitem desenvolver a criticidade dos estudantes, afim de compreenderem a realidade, identificando as possíveis necessidades de transformações. Verifica-se, que o ato de realizar questionamentos, promover pesquisas e investigações, propor a resolução de problemas presentes no cotidiano do aluno, desenvolver dúvidas para instigar os estudantes a procurar respostas são ações educativas do professor que colaboram para o discernimento do processo da Alfabetização Científica.

Durante as ações educativas, é importante que o professor da disciplina de Ciências promova oportunidades para que os alunos possam se sentir agentes na sala de aula, e não passivos, pois sabe-se que a coletividade contribui na construção do conhecimento. A relação do ensino e aprendizado não é um processo mecânico onde prevalece somente a transmissão e a recepção do conhecimento, é um movimento dinâmico de integração entre os saberes, no qual se constitui mediante as verbalizações entre professor e aluno.

Portanto, torna-se relevante "buscar fazer uso da fala e da escuta de modo a contribuir para a criação de significados úteis para a aprendizagem de Ciências" (MORAIS; ANDRADE, 2009, p.51). Essa relação harmoniosa entre a linguagem do professor e do aluno, permite ao profissional docente identificar no aluno a evolução em relação aos saberes estabelecidos na construção do conhecimento. 
A disciplina de Ciências é vista pela grande maioria dos professores como uma Ciência neutra, pois os conteúdos que determinam o Plano de Trabalho Docente são abordados em sala de aula de maneira inquestionável e já finalizado. Para contemplar um ensino aprendizado no ensino de Ciências que permita a clarificação dos conteúdos, é preciso que os professores busquem novas ferramentas de ensino, desprendendo-se dos livros de textos, pois o uso desse material intensifica o método de memorização de conceitos e a exposição teórica dos conteúdos.

Para que ocorram as mudanças no ensino de Ciências, necessita-se um trabalho de revisão dos conteúdos, o professor deve realizar questionamentos sobre, o que realmente o aluno necessita aprender para compreender a Ciência como parte da sua vida diária? Além desse questionamento, é necessário repensar nos métodos e práticas de ensino e promover momentos de participação e colaboração dos estudantes durantes as ações didáticas. Desse modo, para que as mudanças no ensino de Ciências se intensifiquem, é preciso "planejar as aulas baseadas na investigação científica, desafiando a si e aos estudantes, proporcionando a construção do conhecimento científico pode colaborar para práticas pedagógicas inovadoras" (PFIFFER et al, 2013, p.18).

O desenvolvimento de sequências didáticas no qual os alunos são desafiados a resolver problemas presentes na sua realidade sem a solução imediata, permite à busca de informações específicas bem como a discussão argumentativa entre os estudantes, o que possibilita a investigação científica por meio da resolução do problema.

De acordo com Sasseron e Carvalho (2007), a aproximação dos estudantes com a cultura científica por meio da investigação implica em harmonizar e proporcionar diferentes espaços e tempo para que os alunos possam estudar os conteúdos de caráter científico utilizando-se de ferramentas culturais próprias do cenário que estão envolvidos. Trata-se de trabalhar o conhecimento científico de modo que os estudantes utilizem esses conhecimentos em sua prática social.

Sendo assim, é preciso que os conteúdos científicos sejam trabalhados em sala de aula de maneira contextualizada, dando sentido para a importância dessa área do conhecimento no cotidiano do estudante. Para isso, é preciso renovar os propósitos do ensino.

Apesar da necessidade de um ensino contextualizado culturalmente, verificase que a abordagem dos conceitos científicos é transformada em palavreados repetidos pelos estudantes sem a devida compreensão e significação cultural (SANTOS, 2007). No caso do Ensino de Ciências, os conteúdos trabalhos com ênfase na memorização de conceitos científicos, torna-se um empecilho para o entendimento da ciência.

As visões empobrecidas da natureza da ciência transmitida por alguns professores pode causar o desinteresse de muitos estudantes. Sabe-se que um dos objetivos do ensino de Ciências é compreender os conceitos científicos, mas o entendimento desses conteúdos não se dá por meio da apresentação de conhecimentos já elaborados, é necessário apresentar os assuntos científicos aos estudantes por meio de uma abordagem acessível, no qual é possível discutir, questionar e compreender os significados. 
Ensinar ciências, portanto, tem como critérios propor atividades abertas no cotidiano escolar, ou seja, atividades que possibilitem variadas resoluções, onde é possivel diversificar o contexto em que se propõe a aplicação de uma estratégia, fazendo com que o estudante trabalhe com diferentes conceitos nas situações das diferentes áreas do conhecimento. (MORAIS, ANDRADE, 2009, p.13).

Criar espaços que potencializam as aprendizagens nas diferentes áreas do conhecimento bem como a abordagem histórica dos conhecimentos, conduz a um ensino de Ciências mais enriquecedor. O trabalho com a história dos saberes, possibilita a discussão da origem e transformação do conhecimento, ou seja, sua evolução ao longo do tempo, permitindo aos estudantes o reconhecimento de que os conhecimentos científicos foram construídos para responder perguntas que foram realizadas diante de uma problemática. A história social da Ciência, pode contribuir na motivação dos alunos, pois conhecer o passado histórico da construção do conhecimento científico, permite aos estudantes perceberem que os cientistas também tiveram dúvidas e incertezas durante seus estudos, o que possibilita um novo olhar sobre suas inquietações durante a aprendizagem.

A história do conhecimento científico, facilita a compreensão do aluno sobre a concepção do que é Ciência, pois quando se busca o estabelecimento do diálogo entre o presente e o passado, desmitifica-se a ideia de que os grandes cientistas da história da Ciências realizaram seus estudos trancados em seus laboratórios isolados da sociedade, e que esses conhecimentos já construídos são inquestionáveis e acabados.

Por meio das reflexões históricas da construção do conhecimento científico, torna-se possível "acreditar na nossa capacidade de construtores da História. Nós fazemos o hoje. Nós, afortunadamente, estamos inventando o agora" (CHASSOT, 2011, p.114). Sendo assim, a visão histórica do conhecimento possibilita ao estudante identificar as constantes transformações e os novos saberes inerentes a ciência.

É preciso, realizar propostas de ensino no qual os estudantes possam reconhecer e compreender que a Ciência está presente em tudo, nos alimentos, remédios, eletrônicos, medicina, ou seja, no ambiente, mostrando-lhes que eles mesmos podem ser os próximos autores do fazer Ciência.

Além do entendimento de que a Ciência está em tudo, é necessário que os alunos tenham acesso a "[...] informações sobre temas relacionados à Ciência, à tecnologia e aos modos como estes empreendimentos se relacionam com a sociedade e com o meio-ambiente (SASSERON; CARVALHO, 2008, p.04). Desse modo, "devemos ajudar os estudantes a desenvolver perspectivas da ciência e da tecnologia, que incluam a história das ideias científicas, a natureza da ciência e da tecnologia e o papel de ambas na vida pessoal e social" (CACHAPUZ, 2011, p. 23).

Hoje a Ciência está estreitamente ligada com a tecnologia, o que torna possível a verificação dos seus sucessos e fracassos em razão da sua relação com as atividades sociais e culturais do ser humano. $O$ ensino de Ciências precisa contemplar não apenas o conhecimento científico como também o tecnológico, pois o conjunto desses conhecimentos permeiam a vida cotidiana do estudante. Nesse sentido, quando se objetiva a alfabetização científica é essencial que os conhecimentos sobre Ciência Tecnologia e Sociedade (CTS) sejam inseridos na prática docente. 
Assim, Auler e Delizoicov (2001) afirmam que a Alfabetização Científica e Tecnológica pode ser concebida segundo duas perspectivas, a reducionista e a ampliada. A perspectiva reducionista refere-se ao ensino de conceitos no qual possui como meta a transmissão do conhecimento científico, pouco se desenvolve a criticidade mediante as implicações da ciência e tecnologia, ignorando-se a existência de mitos, tais como: a) tecnocracia: modelo pelo qual a Ciência é valorizada na sociedade como instância absoluta; b) perspectiva salvacionista: a ciência e tecnologia direcionam o progresso e são criadas para resolver os problemas da sociedade e; c) determinismo tecnológico no qual a mudança social coopera com a inovação tecnológica. Já na perspectiva ampliada, a finalidade é relacionar os conhecimentos da ciência, tecnologia e sociedade em uma leitura crítica do mundo, um ensino de conceitos associado ao reconhecimento de mitos relacionados à Ciência e tecnologia.

Observa-se que os conhecimentos que envolvem a CTS estão pouco presentes na abordagem dos conteúdos da disciplina de Ciências, e quando trabalhados são expostos de maneira conceitual, não havendo oportunidades para debates e diálogos referentes à CTS. Estes conhecimentos não podem ser vistos como inquestionáveis, pois estão relacionados com a saúde, moradia, locomoção, ou seja, com o bem estar do sujeito, não podendo deixar de esquecer que ao mesmo tempo que traz benefícios para a comodidade na vida social do indivíduo, pode resultar em sérios problemas ambientais. As problemáticas devem ser discutidas no ambiente escolar para que os estudantes possam contribuir nas decisões críticas relacionadas as implicações das frequentes inovações tecnológicas.

A compreensão sobre os benefícios e consequências que os estudos científicos trazem, é essencial para que o aluno possa identificar e argumentar as possíveis formas de intervenção da ciência e da tecnologia. Perceber as consequências das inovações tecnológica, como: poluição gerada por indústrias, uso desenfreado de agroquímicos, catástrofes ambientais causadas por acidente nuclear e dentre outros exemplos, contribuem para a formação da criticidade do estudante, bem como reflexões sobre os impactos gerados na natureza.

Cabe destacar, a possibilidade dos docentes podem apresentar certas dificuldades na abordagem dos conteúdos CTS. Dessa forma, os recursos paradidáticos se apresentam como importantes instrumentos que podem colaborar no trabalho a ser realizado pelo professor, dentre eles destaca-se: os programas de TVs educativas e de divulgação científica, revistas, textos de jornais, entre outros. Tais instrumentos, devem estar presentes de maneira planejada e articulada no processo de ensino e aprendizado, para que os objetivos do processo da alfabetização científica com a abordagem CTS possam ser alcançados.

Em sala de aula, o aluno que consegue identificar e se posicionar criticamente mediante as implicações das novidades científicas, durante as interações sociais extra escolares, terá mais oportunidades de se relacionar de maneira participativa e crítica nas decisões que afetam a sua vida social e pessoal.

No decorrer das discussões dos parágrafos anteriores, foi abordado alguns aspectos relacionados a alfabetização científica. A partir disso, destaca-se o estudo de Demo (2010) no qual descreve algumas condições que se fazem necessárias para iniciar o processo de alfabetização científica, dentre elas: ultrapassar o instrucionismo, o aluno deve participar ativamente no processo da aprendizagem; habilidade científica do professor, em que ele, mais do que o aluno deve dominar 
as técnicas da escrita; ambiente escolar focado na educação científica, com materiais didáticos e laboratórios voltados para tal objetivo; oportunidades de experimentos científicos, tanto no ambiente escolar, quanto nos espaços informais de ensino; didáticas das problematizações propondo situações a serem enfrentadas por meio do método científico; materiais didáticos, com qualidade científica, ao invés de livros didáticos ou apostilas impressas.

Dentre as condições para se promover a Alfabetização Científica, a disposição do professor em produzir conhecimentos por meio da pesquisa na área de Ciências, é que a se faz mais importante, pois o professor que possui conhecimentos e experiências sobre a pesquisa e a técnica científica, não terá dificuldades em desenvolver atividades que fomentam a alfabetização científica, como atividades lógicas e experimentais.

Além de possuir as habilidades científicas, o professor em suas ações didáticas deve apresentar os conhecimentos com criatividade, relacionando-os com o contexto no qual os estudantes estão inseridos, pois sabe-se que os sujeitos lidam de maneira mais eficiente quando os conhecimentos são familiarizados com o seu cotidiano, o que torna esse saber mais satisfatório e significante. De acordo com Ferreira (2013, p. 28):

[...] o professor precisa desenvolver capacidades, reconhecer as transformações tecnológicas de informação em sala de aula, atender as diversidades culturais, respeitando as diferenças, investindo na atualização científica, estratégias e cultural, integrando no exercício de sua docência a dimensão afetiva, bem como orientando os alunos sobre valores e atitudes. É necessário planejar, pois as novas tecnologias são instrumentos para os educandos e educadores no processo da formação de cidadãos.

Diante desse contexto, ressalta-se a importância de discutir a formação dos professores, para que as ações de transformação do ensino informativo para o transformador e criativo possam ser concretizadas, o que pode se dar a partir de um trabalho mais abrangente na perspectiva da formação docente. Existe a necessidade de compreender que a Ciência não é somente um conjunto de conhecimentos científicos teóricos, mas se constitui diante das teorias e experimentos pelo qual se vê o mundo.

Além da formação de professores, torna-se necessário refletir sobre a atual situação das escolas e colégios da rede estadual de ensino, percebe-se que a estrutura escolar, em muitos casos, torna-se um empecilho para a realização de atividades de caráter investigativo, o espaço escolar carece de laboratórios de ciências equipados e instrumentos didáticos. Cabe destacar, que as atividades investigativas podem ser adaptadas diante dos recursos que a escola possui, no entanto é necessário reconhecer que existe a necessidade de se ter condições e materiais didáticos adequados para o desenvolvimento das atividades dentro da perspectiva da Alfabetização Científica.

Apesar das dificuldades encontradas, é preciso que o educador desenvolva estratégias com o propósito de superar a falta de recursos encontrados no ambiente escolar. Para Santos (2007) o objetivo da Alfabetização Científica não é somente formar futuros cientistas, mas tornar a educação científica uma ferramenta cultural. Nesse sentido, o uso de meios informais de divulgação científica, como textos de revistas e jornais, utilização de programas televisivos e radiofônicos podem popularizar o conhecimento científico, além dessas 
atividades, visitações em espaços não-formais de ensino em zoológicos, museus de ciência, parques de proteção ambiental e dentre outros locais, tornam-se importantes meios para se trabalhar os valores da ciência inseridos na prática social.

Os espaços não-formais de ensino, se constituem como importantes locais de divulgação do conhecimento científico, os centros e museus de Ciências possibilitam a aproximação da Ciência com a sociedade, além disso, torna possível o desenvolvimento de discussões sobre os significados da Ciência, o reconhecimento do cientista bem como os procedimentos utilizados durante as investigações. Esses espaços geram várias possibilidades de aprendizado, o que intensifica a necessidade de estarem aliado ao ambiente escolar.

Para Lorenzetti e Delizoicov (2001) os espaços não-formais de ensino, propiciam aos estudantes a visão de que a Ciência é parte de seu mundo e não um conteúdo separado. Portanto, pode-se afirmar que o processo de Alfabetização Científica não acontece somente na escola, pois os conteúdos científicos também estão presentes nas relações do cotidiano, sendo assim, existe a necessidade de mostrar para o aluno, onde e como buscar os conhecimentos científicos.

Portanto, são várias as ações necessárias para se promover o processo de Alfabetização Científica, que é um trabalho coletivo, e que requer a participação da sociedade, desse modo, não se inicia e termina nos estabelecimentos de ensino, mas envolve toda vida do sujeito.

\section{ENCAMINHAMENTOS METODOLÓGICOS}

A metodologia que retrata a abordagem deste trabalho de pesquisa é classificada como qualitativa por ser "[...] uma ciência baseada em textos, ou seja, a coleta de dados produz textos que nas diferentes técnicas analíticas são interpretadas hermeneuticamente" (GUNTHER, 2006, p.202). Os pesquisadores que optam pela pesquisa qualitativa buscam analisar o contexto, e se possível realizam a integração com o processo do objeto de estudo que implica em uma melhor compreensão do fenômeno (NEVES, 1996).

A partir desses princípios e com o intuito de analisar como o processo da Alfabetização Científica vêm sendo trabalhada nas práticas pedagógicas dos professores de Ciências, optou-se pela pesquisa de campo como tipologia do trabalho a ser realizado e que possibilitou ao pesquisador um contato direto com ambiente escolar, espaço que se encontravam os participantes.

Para gerar as informações dessa pesquisa elaboramos um roteiro estruturado para a entrevista, composto por tópicos de discussões diretos e objetivos, facilitando assim, a compreensão dos itens pelo entrevistado. Cabe ressaltar, que durante a entrevista foi utilizado um gravador de voz e que em seguida, o material foi transcrito para viabilizar a análise dos relatos dos professores. Com o intuito de preservar a identidade dos professores, durante a transcrição das entrevistas optou-se por utilizar nomes fictícios, dentre eles: Ana, Alice, Carlos e João.

O município de Planalto possui um total de seis escolas estaduais, dentre elas, duas escolas estão localizadas na cidade e as outras quatro são escolas do campo. As entrevistas foram realizadas com quatro professores que lecionavam a disciplina de Ciências, nas turmas do 9a ano do ensino fundamental, destes haviam 
dois professores que trabalhavam em dois estabelecimentos escolares. Estes profissionais da educação, apresentaram muitas vivências e experiências, pois lecionam a disciplina de Ciências há vários anos. Cabe destacar, que as entrevistas foram realizadas no próprio ambiente escolar, no período da hora atividade do professor.

A etapa de análise das informações, oriundas das entrevistas representam um momento de extrema importância para a pesquisa, diante desta preocupação, a estratégia utilizada foi a metodologia da Análise Textual Discursiva (ATD) proposta por Moraes e Galiazzi (2007).

A análise textual discursiva é um processo que se inicia com a separação dos textos em unidades de significados, que podem gerar outros conjuntos de unidade provenientes da interlocução teórica, empírica ou por meio das interpretações feitas pelo pesquisador. A partir desse movimento, exercita-se a apropriação das falas de outras vozes para uma melhor compreensão do texto. Posteriormente, passa-se a fazer a articulação de significados, podendo gerar várias categorias de análise, dessa forma, a análise textual discursiva se constitui como ferramenta mediadora na produção de significados, que só pode ser alcançada a partir do movimento intenso de interpretação e produção de argumentos, que irá gerar meta-textos analíticos e que irão formar textos interpretativos (MORAES; GALIAZZI, 2007).

\section{ANÁLISE}

Por meio das unidades de significados provenientes dos relatos dos professores, emergiram duas categorias de análise as quais serão apresentadas e discutidas na sequência da escrita. A primeira categoria, visa discutir a concepção dos professores de Ciências a respeito da abordagem da Alfabetização Científica, já a segunda categoria emergiu diante da fala dos docentes, pois os mesmos afirmaram durante as entrevistas, a necessidade do contínuo processo de formação na carreira do profissional docente.

\section{I) A COMPREENSÃO DOS PROFESSORES SOBRE A ALFABETIZAÇÃO CIENTÍFICA}

Ao longo da história, o Ensino de Ciências passou por vários processos de reformas, devido as influências políticas e sociais presentes em cada contexto, hoje uns dos objetivos é promover a Alfabetização Científica, que busca a formação de cidadãos críticos capazes de intervir na sociedade em que vivem. Desse modo, salienta-se a importância do papel do professor para relacionar a Ciência ensinada na escola com as situações presentes no cotidiano.

Considerando a importância do papel do professor para contemplar os objetivos da Alfabetização Científica, durante as entrevistas os mesmos foram questionados sobre as competências que um sujeito deve ter para ser considerado alfabetizado cientificamente.

As competências e habilidades do sujeito alfabetizado cientificamente estão relacionadas com a compreensão básica de termos e conceitos científicos fundamentais; o reconhecimento de que os saberes estão em constantes transformações; percepção das implicações e aplicações das ciências e a relação 
com a Ciência Tecnologia e Sociedade; e o desenvolvimento de atitudes críticas diante dos possíveis problemas sociais. Essas competências descritas, nortearam o processo de análise das entrevistas realizadas com os professores.

Já nas primeiras narrativas de alguns professores infere-se que existem lacunas na compreensão dessa abordagem.

Pois é, a gente primeiro vai ter que ver, se situar no alfabetizado cientificamente para depois saber o que se espera do aluno (João).

Complicado, só vontade não baste né, ele vai ter que ter interesse, vai ter que ter bastante tempo para estudar essa parte ali, para formular o conhecimento dele, porque chegar e falar assim ó professora isso daqui, tá mais e daí? (Carlos).

No primeiro relato, o professor apresentou autenticidade em sua resposta, reconheceu a necessidade de primeiramente conhecer a proposta da Alfabetização Científica para depois desenvolver atividades desse caráter em sala de aula. Já para o outro professor entrevistado, verificou-se a falta de compreensão da proposta, pois priorizou somente as ações do estudante, no qual deixou de destacar a importância do papel do professor no processo da Alfabetização Científica.

O planejamento de ações didáticas e pedagógicas que contemplam a Alfabetização Científica, possibilita o reconhecimento do uso social dos saberes científicos bem como o desenvolvimento da criticidade dos estudantes. Os objetivos do ensino de Ciências só serão contemplados quando houver o interesse coletivo entre o professor e o aluno em pesquisar e construir juntos o conhecimento.

Se faz necessário reconhecer que as dificuldades de compreensão do processo da Alfabetização Científica podem estar relacionadas com a formação inicial desses professores. Para Silva e Bastos (2012) ao repensar a formação de professores de Ciências é necessário reconhecer que a valorização do conhecimento científico, exige do profissional docente um ensino de Ciências menos dogmático, acrítico e descontextualizado. Portanto, "devemos fazer do ensino de Ciências uma linguagem que facilite o entendimento do mundo pelo alunos e alunas" (CHASSOT, 2011, p.100).

O ensino de Ciências passou de uma fase de apresentação da Ciência como neutra para uma visão interdisciplinar (KRASILCHIK, 2000). Os professores entrevistados já possuem uma longa carreira docente, portanto, a formação inicial desses profissionais da educação pode ter acompanhado outra perspectiva do ensino de Ciência com influências culturais ou políticas presentes naquele contexto social.

Dessa forma, justifica-se a necessidade dos professores estarem em constante formação. Nessa perspectiva, o reconhecimento da importância do processo de formação permanente, só é possível quando o professor realiza contínuas reflexões sobre as suas ações didáticas, no qual proporciona novos questionamentos e transformações no seu fazer pedagógico.

O movimento de reflexão permite o repensar sobre os objetivos do ensino e aprendizado, bem como sobre a importância dos saberes sociais que se fazem relevantes para a formação de cidadãos críticos e responsáveis. Durante a 
entrevista, quando a professora Alice foi questionada sobre as competências necessárias para o aluno ser considerado alfabetizado cientificamente, pode-se constatar uma ausência de coerência em relação a proposta da Alfabetização Científica.

Ter o conhecimento pra (sic)... o mínimo necessário para o mercado de trabalho né, ele tem que ter esse conhecimento... manipular, questionar esse conhecimento, ter atitude para desenvolver o conhecimento científico sozinho, saber analisar.

A entrevistada destacou que uma das habilidades da Alfabetização Científica é a obtenção de conhecimentos para o mercado de trabalho. No entanto, quando se relaciona o mercado de trabalho com a Alfabetização Científica é no sentido de formar cidadãos críticos, capazes de realizar atividades cooperativas, promover técnicas sustentáveis e mudanças na realidade excludente, e não como um modelo empresarial de ensino. Ao mesmo tempo, o professor destacou algumas das competências que se fazem importantes para a formação de um estudante capaz de reconhecer, identificar e utilizar os saberes científicos em benefício próprio.

Já para a visão da professora Ana, as competências necessárias para o sujeito ser considerado Alfabetizado Cientificamente estão relacionadas com o desenvolvimento do senso crítico.

É, ler um texto por exemplo e interpretar e discutir aquilo, duvidar daquilo, tentar achar resposta daquilo e não aceitar aquilo como pronto, eu acho que no momento que o aluno começar a questionar sobre certas situações ele vai ser um aluno crítico, que saiba diferenciar o que é um mito do que é uma verdade, do que é real do que não é [...]

O ensino das ciências deve "fomentar a aquisição de conhecimentos e o desenvolvimento de capacidades de pensamento crítico dos alunos que lhes permitam enfrentar as mudanças e participar numa sociedade democrática" (KONDER, 1998, p.58). Para que os objetivos da alfabetização científica sejam contemplados, a professora relata que durante as aulas de Ciências procura promover ações que possibilitam a realização de atividades como:

Pesquisas, trabalhos práticos mesmos que eles tenham que apresentar, textos que levem a isso. Eu procuro trabalhar bastante a questão da Ciência, Tecnologia e Sociedade [...] porque eu acho que a ciências deve estar voltada para o social para a comunidade, de uma forma mais contextualizada para eles, não adianta muito eu dar uma ciência muito longe deles que não vão gostar. Eu acho que pesquisas, experimentos práticos, leituras de textos científicos mesmos, pra que eles entendam a história da ciência, da evolução da ciência, a despertar o interesse deles por isso (Ana).

Essas ações pedagógicas realizadas pelo professor, possibilitará aos alunos "ver e compreender o mundo com maior criticidade e com conhecimentos para discernir, julgar e fazer escolhas conscientes em seu cotidiano, com vistas a uma melhor qualidade de vida" (VIECHENESKI; CARLETTO, 2013, p.10).

Entre as narrativas apresentadas na entrevista, esse foi o único professor que enfatizou a abordagem CTS no ensino de ciências, verificou-se que em seu relato destacou a importância de se trabalhar com questões que envolvem o contexto social do aluno. Esse olhar para o Ensino de Ciências, corrobora com as perspectivas de Pinheiro et al. (2007) no qual destaca que o ensino por CTS visa 
"ressaltar a importância social da ciência e da tecnologia, de forma a enfatizar a necessidade de avaliações críticas e análises reflexivas sobre a relação científicotecnológica e a sociedade" (p.74). Portanto, a abordagem CTS possibilita um novo olhar sobre os avanços tecnológicos, pois sabe-se que além dos benefícios o desenvolvimento tecnológico pode causar novos problemas sociais e ambientais.

A sociedade em geral, apresenta dificuldades para identificar e se sensibilizar diante dos possíveis problemas decorrentes dos avanços tecnológicos, pois pouco se questiona sobre os impactos causados. Sendo assim, destaca-se a necessidade de se trabalhar com o enfoque CTS na área educacional, para que os futuros cidadãos sejam capazes de participar das decisões que afetam o meio em que vivem, exigindo-se um posicionamento quanto as ações para solução dos possíveis problemas.

Além disso, cabe ressaltar que a abordagem dos conteúdos de Ciências com enfoque CTS proporciona uma maior contextualização e significado ao aprendizado, pois permite a relação do conhecimento científico com o contexto social do aluno, evitando a fragmentação do saber. Por meio do trabalho interdisciplinar é possível a desfragmentação do ensino, bem como a realização de propostas que contemplam a união de diferentes conhecimentos, afim de proporcionar um melhor entendimento dos fenômenos presentes no contexto social que o sujeito está inserido. Portanto, os conhecimentos obtidos por meio dos conteúdos específicos devem ir além do saber sistematizado e fragmentado, "esse conhecimento adquirido pelo estudante deve trazer-lhe satisfação de apropriar-se de mais saber, para poder se entender, entender o outro, entender o mundo" (PEÑA, 2011, p.61).

Cabe destacar, que no decorrer da entrevista a professora Ana evidenciou que o seu entendimento e o desenvolvimento da abordagem da Alfabetização Científica em sala de aula, foi possível por meio da participação do Programa de Desenvolvimento Educacional (PDE) que é uma política pública do Estado do Paraná que estabelece o diálogo entre os professores do ensino superior e os da educação básica. Esse relato, destaca mais uma vez a importância do contínuo processo de formação na carreira do profissional docente, aspecto esse que gerou uma análise exclusiva, como pode-se observar na próxima categoria.

\section{II) FORMAÇÃO PERMANENTE}

O contexto social e educativo está em constante transformação e grande parte das mudanças são decorrentes das diferentes atividades de pesquisa que possibilitam novos saberes científicos e consequentemente novas mudanças no aprender. Por meio dessa dinâmica surgem outros desafios para a profissão docente, exigindo dos professores a contínua necessidade de se atualizar frente aos novos conhecimentos.

Nas outras categorias de análise, é evidente os impactos da ausência e ou da presença da formação continuada para o entendimento do processo da Alfabetização Científica. Nas narrativas de alguns dos professores entrevistados, os mesmos reconheceram a necessidade de se atualizarem 
Porque primeiro quem tinha que estar atualizado para isso tinha que ser nós professores e a gente busca isso por conta própria por informação, leitura de textos (Ana).

Então é uma questão nova para gente né. Eu acho que primeiro a gente tem que realmente vê de que forma essa prova vai ser proposta, o que eles querem para a gente poder se situar também, porquê essa palavra alfabetização científica a gente não usa. Então assim a gente não usa essa palavra no nosso cotidiano, então é algo que tem que ser construído (João).

No que se refere a formação dos professores, o que se tem presenciado é a realização de cursos de formação oferecidos pela Secretaria da Educação de seus respectivos estados, que na maioria das vezes apresentam temáticas prontas para serem trabalhadas com todos os professores do estabelecimento escolar, desconsiderando os verdadeiros obstáculos a serem superados pelos professores de cada área de ensino. É preciso colocar as inquietações de cada professor como objeto de análise, pois "é preciso analisar o que funciona, o que devemos abandonar, o que temos de desaprender, o que é preciso construir de novo ou reconstruir sobre o velho" (IMBÉRNON, 2009, p.18).

Desse modo, ao propor cursos para a formação continuada dos professores, primeiramente deve-se realizar problematização e investigar as necessidades da ação educativa. Sabe-se que no decorrer do ano letivo os professores participam de cursos de formação continuada, no entanto os relatos das narrativas demonstraram que alguns dos professores da disciplina de Ciências não conhecem a abordagem da Alfabetização Científica, diante disso, se faz o seguinte questionamento: Quais objetivos do Ensino de Ciências estão sendo discutidos nos cursos de formação oferecidos para os professores?

Nesta pesquisa, já foi ressaltado que um dos objetivos do Ensino de Ciências é a Alfabetização Científica. Dessa forma, é essencial que o professor reconheça que o processo da Alfabetização Científica possibilita a compreensão da natureza da Ciência bem como os impactos da Ciência e Tecnologia na sociedade.

O movimento de reflexão sobre a prática docente é um dos caminhos para compreender como vem ocorrendo a aprendizagem dos alunos, o que proporciona a reflexão sobre os objetivos que se pretende almejar com o ensino e aprendizado diante das novas necessidades do contexto educacional, pois sabe-se que um dos caminhos da educação é a transformação social. Portanto, verificou-se a necessidade de se desenvolver novos espaços de formação docente com discussão e reflexão sobre as novas perspectivas e objetivos do ensino, no qual possa se "transformar num espaço de reflexão, formação e inovação para que o professorado aprenda, pois a formação move-se sempre entre a dialética de aprender e desaprender" (IMBÉRNON, 2009, p.106).

\section{CONSIDERAÇÕES FINAIS}

Podemos observar, que a Alfabetização Científica é um dos critérios avaliados nas respostas das questões das avaliações externas do Programa Internacional de Avaliação de Alunos (PISA), desse modo, verifica-se a necessidade de se repensar sobre o que é cobrado pelo programa, e a realidade do ensino de Ciências, pois as condições e oportunidades para alfabetizar cientificamente os estudantes, estão a passos curtos. 
Por meio da discussão da análise desta pesquisa, verificou-se a importância de se discutir os objetivos do Ensino de Ciências, afim de proporcionar o processo da Alfabetização Científica, pois pode-se constatar muitas lacunas inerentes à inserção e compreensão da abordagem da Alfabetização Científica nas práticas pedagógicas, bem como na formação permanente dos professores. No entanto, pode-se observar que os professores que participaram das entrevistas reconhecem a necessidade de se atualizarem quanto aos novos desafios e objetivos presente no ensino de Ciências.

É necessário que iniciativas sejam contempladas, afim de superar essas lacunas presentes na abordagem da Alfabetização Científica, dentre elas deve-se destacar a percepção das transformações que ocorrem na sociedade. Essa atitude possibilita o professor se sensibilizar diante da necessidade de ser um profissional atualizado, sendo capaz de reconhecer os novos conhecimentos e implicações desses saberes nas atividades sociais.

Outro fator a ser destacado, é inerente a necessidade de um olhar mais atento aos cursos de formação que são disponibilizados para os profissionais da educação. Esses devem contemplar as reais necessidades dos professores e dos estudantes que estão presentes no atual contexto educacional. A dinâmica de formação, deve explorar o espírito crítico e investigativo do professor, para que o mesmo possa compreender as mudanças que os indivíduos alfabetizados cientificamente podem promover na sociedade.

Sabe-se que o professor é um dos grandes protagonistas do ensino, portanto, a valorização do professor é essencial para a melhoria da educação, é necessário a disponibilização de recursos e ferramentas de ensino bem como a melhoria dos cursos de formação e das condições de trabalho. A sociedade em geral apresenta diferentes cobranças e responsabilidades do professor, mas os mesmos não são retribuídos com condições e recursos adequados para ensinar e aprender. 


\title{
Teachers' understanding of Scientific Literacy: perspectives and reality for Science Teaching
}

\begin{abstract}
Scientific literacy is an alternative that makes possible the re-signification of science, in which it prioritizes the contextualization of content and the commitment to the formation of critical and prepared citizens to participate in discussions about the advances and implications of science. This research aimed to understand how the approach to scientific literacy has been worked in the classroom by the science teachers of elementary schools in the municipality of Planalto, PR. The methodology that portrays the approach to the research problem is classified as qualitative. For the development of the study, interviews were conducted with four science teachers from the 9th grade of elementary school in the state schools of the municipality of Planalto, PR. The interviews were analyzed based on the Discursive Textual Analysis methodology, in which the following categories emerged: The teachers' understanding of scientific literacy and permanent formation. There was a need to discuss and rethink the objectives of science teaching in order to provide the process of scientific literacy because there are many gaps in understanding this approach. The importance of the continuous process of training in the career of the teaching professional is emphasized.
\end{abstract}

KEYWORDS: Science teaching. Scientific literacy. Permanent training. 


\section{REFERÊNCIAS}

AULER, D; DELIZOICOV, D. Alfabetização Científico - Tecnológica para quê? Ensaio- Pesquisa em Educação em Ciências, Belo Horizonte, v.3, n.1, p.105-115, 2001.

ARAÚJO, I. CHESIINI, T. FILHO, R.J. Alfabetização Científica: Concepções de Educadores. Contexto \& Educação, Unijuí, v.1, n. 94, p.4-26, 2014.

BRASIL. Parâmetros curriculares nacionais: ciências naturais / Secretaria de Educação Fundamental. - Brasília: MEC/SEF, 1997. 136p.

CACHAPUZ, António et al. A necessária renovação do ensino das ciências. 3 ed. São Paulo: Cortez, 2011.

CAISCAIS, M. G.; GHEDIN, E.; TERÁN, A.F. O significado da questão do conhecimento para a alfabetização científica. In: Encontro Nacional de Pesquisa em Educação em Ciências. 2011, Campinas. Anais... VIII ENPEC

CHASSOT, A. Alfabetização científica: questões e desafios para a educação. 5 ed. Ijuí: Unijuí, 2011, p.368.

DEMO, Pedro. Educação e Alfabetização Científica. Campinas, SP: Papirus, 2010.

FERREIRA, R.M.S. Letramento científico: conhecimentos construídos ao longo do ensino fundamental. 2013, p. 82. Diss. (Mestrado em Educação) - Fac. de Educação, PUCRS, 2013.

FREIRE. P. Educação como prática da liberdade. São Paulo: Paz e Terra, 1980.

GUNTHER, H. Pesquisa Qualitativa Versus Pesquisa Quantitativa: Esta É a Questão? Psicologia: Teoria e Pesquisa, Brasília, v.22, n. 2, p.201-210, 2006.

IMBÉRNON, F. Formação permanente do professorado: novas tendências. São Paulo: Cortez, 2009.

KRASILCHIK, M. Reformas e realidade: o caso do ensino das ciências. Perspec, São Paulo, v.14, n.1, p. 85-93, 2000.

KONDER, O. Ensino Ciências no Brasil: Um breve resgate histórico. In: CHASSOT, A. e Oliveira J.R. (org). Ciências, ética e cultura na Educação. São Leopoldo: Ed. UNISINOS, 1998, p.25.

LORENZETTI, L.; DELIZOICOV, D. AC no contexto das séries inicias. Ensaio - 
MORAIS, M. B.; ANDRADE, M. H. de P. Ciências: ensinar e aprender. Belo Horizonte: Dimensão, 2009.

MORAIS R.; GALIAZZI, M.C. Análise textual discursiva. Ijuí: Ed. Unijuí, 2007.

MONTENEGRO, P. P. Letramento científico: o despertar do conhecimento das ciências desde os anos iniciais do ensino fundamental. 2008. 200 f. Dissertação (Mestrado em Educação) - Universidade de Brasília, Brasília, 2008.

NEVES, L. J. Pesquisa Qualitativa - Características, Usos e Possibilidades. Caderno de Pesquisas em Administração, São Paulo, v.1, n. 3, p.1-5, 1996.

OECD. Programa Internacional de Avaliação dos Estudantes. Sumário executivo, Brasil, 2015.

PFIFFER, C. S. et al. Contribuições da Interdisciplinaridade para a Alfabetização Científica no Ensino Médio. In: Simpósio Internacional sobre Interdisciplinaridade no Ensino, na Pesquisa e na Extensão - Região Sul, 2013, Anais... Florianópolis: SIIEPE- SUL, 2013.

PEÑA, M. Interdisciplinaridade: questão de atitude. In: FAZENDA, I. Práticas Interdisciplinares da escola. São Paulo: Cortez, 2011.

PINHEIRO, N.; SILVEIRA, R.; BAZZO, W. Ciência, tecnologia e sociedade: a relevância do enfoque CTS para o contexto do ensino médio. Ciência \& Educação, v.13, n.1, 2007.

ROTHBERG, D.; QUINATO, G. A. Alfabetização científica em nível médio e a preparação para o processo de tomada de decisões. Revista Triângulo, São Paulo, v. 4, n.1, p.1-10, 2012.

SANTOS, W. L. P. Educação científica na perspectiva de letramento como prática social: funções, princípios e desafios. Revista Brasileira de Educação, Rio de Janeiro, v. 12, n.36, p. 474-492, 2007.

SASSERON, L.H.; CARVALHO, A.M.P. Ensino por CTSA: Almejando a alfabetização científica no ensino fundamental. In: Encontro Nacional em Pesquisa em Educação, Anais... Bauru: VI ENPEC, 2007.

SILVA, V. F.; BASTOS, FERNANDO. Formação de Professores de Ciências: reflexões sobre a formação continuada. Alexandria Revista de Educação em Ciência e Tecnologia, Santa Catarina, v. 5, n. 2, p. 150-188, 2012.

VIECHENESKI, J.P.; CARLETTO, M. Por que e para quê ensinar ciências as crianças. 
Recebido: 29 mai. 2017

Aprovado: 21 jul. 2017

DOI: $10.3895 /$ actio.v2n1.6724

Como citar:

OLDONI, J. F. W. B.; LIMA, B. G. T de. A compreensão dos professores sobre a Alfabetização Científica: perspectivas e realidade para o Ensino de Ciências. ACTIO, Curitiba, v. 2, n. 1, p. 41-59, jan./jul. 2017. Disponível em: <https://periodicos.utfpr.edu.br/actio>. Acesso em: XXX.

Correspondência:

Josiani Fátima Weimer Baierle Oldoni

Avenida Espírito Santo, n 1449. Centro. Capanema, Paraná, Brasil.

Direito autoral: Este artigo está licenciado sob os termos da Licença CreativeCommons-Atribuição 4.0

Internacional.

(c) (1) 